\title{
EL SISTEMA VERBAL EN EL ESPAÑOL DE LA ARGENTINA: RASGOS DE UNIDAD Y DE DIFERENCIACIÓN DIALECTAL
}

\author{
Nélida Esther Donni de Mirande \\ CONICET. Argentina
}

1. Es nuestro propósito exponer algunas características de las formas personales que conforman el sistema verbal en la Argentina, atendiendo a las convergencias y divergencias, a los rasgos de unidad y de diferenciación dialectal en el país. Y esto porque, como lo ha señalado Manuel Alvar, la "lengua, desde un punto de vista sociológico, no acaba nunca de nivelarse, sino que su propia vida es un ser dialectal... El fraccionamiento amenaza continuamente, sea por la extensión en el espacio, sea por la distribución en grupos o estratos sociales" ${ }^{1}$.

1.1. En primer término, aclaramos que la base principal de este trabajo es el examen de aspectos del sistema tal como se nos presenta en la dilatada región que hemos llamado "litoral-pampeana", y que abarca el sur del litoral fluvial y todo el litoral marítimo argentino (provincias de Santa $\mathrm{Fe}$, Entre Ríos, Buenos Aires y todas las patagónicas), así como una parte de la zona central pampeana (sudeste de la provincia de Córdoba y la provincia de La Pampa $)^{2}$. Los datos de esta área serán cotejados con hechos registrados

1 «engua y sociedad que integra En torno a la sociolingüfstica, de M. Alvar y J. M. Lope Blanch, México, 1978, págs. 5-31.

2 Acerca del problema de la delimitación de áreas dialectales en Argentina, deben verse El español de la Argentina, 2." ed., Buenos Aires, 1964, de Berta E. Vidal de Battini y *El problema de la división del español americano en zonas dialectales*, trabajo de J. P. Rona incluido en Presente y futuro de la lengua española, I, Madrid, 1964, págs. 215-226. Aquí Rona reduce a cuatro las cinco zonas que habla delimitado Vidal de Battini. Pero ello no es suficiente y nosotros en el trabajo «Sobre la variación diatópica del español en la Argentinaw, en prensa en Actas del II Congreso Nacional de Lingüistica de San Juan (Argentina), hemos señalado más áreas sobre la base de cuatro fenómenos (el yefsmo, el zef́smo, las formas verbales del voseo en el presente de indica- 
en el noroeste, centro y nordeste de Argentina, gracias a investigaciones propias y de distintos estudiosos de la lengua.

1.2. Si bien en esta oportunidad ocupa un lugar destacado la variación diatópica, no olvidamos, y así lo señalamos cuando es pertinente, que en cada punto geográfico existen variaciones diastráticas y/o diafásicas en el uso lingüístico y que las pautas de variación en un sentido no son las mismas que en otro u otros, al menos en ciertos casos. Por lo demás, también hay diferencias diacrónicas que interesan, es decir, procesos de cambio en distintos grados de desarrollo a partir de la variación sincrónica ${ }^{3}$. Claro está que son más notables las variaciones fonológicas o léxicas, pero también existen diferencias en el plano morfosintáctico, como en seguida veremos.

2. Empezaremos por los fenómenos que atañen a la morfología del verbo debidos a la característica tal vez más llamativa del diasistema argentino: el voseo. Este es en el país predominantemente homogéneo con referencia al uso de pronombres $y$, en menor medida, al empleo $d$ formas verbales. De acuerdo con esta situación, la Argentina forma parte de un grupo de países en el que figuran casi toda Costa Rica, Honduras, Guatemala, Nicaragua, El Salvador y parte de México (estado de Chiapas), frente a otros en los que se usa el pronombre $t \dot{u}$ con formas verbales de segunda persona singular, exclusivas o predominantes (España, México, Cuba, Puerto Rico, Santo Domingo, Panamá, costa atlántica de Colombia y Venezuela, oriente de Ecuador y la mayor parte del Perú), en tanto que el grupo integrado por Chile, Paraguay, Uruguay, Bolivia, partes de Ecuador, Colombia y Venezuela, muestra variaciones geográficas o sociales entre voseo y tuteo ${ }^{4}$.

tivo y la extensión de la $/ \overline{\mathrm{r}} /$ vibrante). De todos modos, para este problema resulta imprescindible realizar nuevos trabajos de geografía lingülstica.

3 De algunas variaciones fonológicas y morfosintácticas nos hemos ocupado en «La variedad del español en la Argentinaw, lefdo en el II Simposio Internacional de Lengua Española de Las Palmas de Gran Camaria (1981).

- De acuerdo con datos trafdos por Vidal de Battini, ob. cit., por E. Tiscornia en La lengua de Martín Fierro, Buenos Aires, B.D.H. III, 1930; por A. Rosenblat en *Notas de morfología dialectal», en El español de Nuevo México, II, Buenos Aires, B.D.H. II, 1946, de A. Espinosa, etc. Más recientemente trataron el tema Charles F. Kany en Sintaxis bispanoamericana, Madrid, 1969, págs. 77-121, y, en especial, J. P. Rona en Geografia y morfología del voseo, Pôrto Alegre, 1967. También R. Lapesa en Historia de la lengua española, 8." ed., Madrid, 1980, trata el voseo americano. Fundamental para el estudio de estas y otras muchas cuestiones de la historia del español es la excelente Morfología bistbrica del español, Madrid, 1983, de Manuel Alvar-Bernard Pottier. En «Las formas verbales de segunda persona y los orígenes del voseo», Actas del III Congreso Internacional de Hispanistas, México, 1970, págs. 519-531, R. Lapesa se ocupó del tema también en el aspecto histórico. Germán de Granda trae abundante bibliografía y se detiene en la interpretación histórica y social del problema, en «Las formas verbales diptongadas en el voseo hispanoamericano. Una interpretación sociohistórica de datos dialectales», trabajo incluido en el volumen dedicado a Estudios lingüísticos 
2.1. Si tenemos en cuenta que se debe entender por voseo no sólo el empleo del $v o s$ en sustitución del $t u ́$ (que seria el voseo pronominal), sino también el uso de formas verbales provenientes del plural como tomás, estas construcciones ya existian, como sabemos, en castellano antiguo ${ }^{5}$. La fórmula primitivamente respetuosa vos fue reemplazando al $t u ́$ aplicado a individuos de baja condición o poca edad. M. Alvar y B. Pottier nos señalan que esto fue un proceso sociológico que, al consumarse, originó el desajuste del uso de un pronombre del plural con un sujeto del singular ${ }^{6}$. La extensión del vos a situaciones familiares, a su vez, requirió la aparición de una nueva forma de mayor cortesia en concordancia con tercera persona verbal: vuestra merced, hoy usted. $\mathrm{Y}$ el vos vulgarizado quedó sólo en algún rincón de España (Asturias, Salamanca), pero se arraigó en América, con formas verbales de plural, cubriendo distintas zonas meridionales y de América Central, a veces en alternancia con el uso del $t u ́$ con formas singulares del verbo.

2.2. El área rioplatense es indudablemente una de las que presentan mayor arraigo de voseo. Sin embargo, en el Uruguay hoy existen zonas de tuteo exclusivo, especialmente en los Departamentos de Rocha, Lavalleja y Maldonado, y otras de alternancia de tuteo y voseo, con formas híbridas ( $t u$ ú cantás o vos cantas, por ejemplo), como en los Departamentos de Rivero y Tacuarembó. En Montevideo se ha señalado que de las cuatro posibles formas resultantes de los cruces de tuteo y voseo pronominal y verhal (T-T = tú cantas; $\mathrm{T}-\mathrm{V}=$ tú cantás $; \mathrm{V}-\mathrm{V}=$ vos cantás $\mathrm{y} \mathrm{V}-\mathrm{T}=$ vos cantas), la norma prefiere el híbrido $\mathrm{T}-\mathrm{V}=t u ́$ cantás, seguido de $\mathrm{V}-\mathrm{V}=$ vos cantás $\mathrm{y}$, por último, $\mathrm{T}-\mathrm{T}=t_{u}$ cantas, en situaciones muy formales ${ }^{7}$. $\mathrm{Y}$ en $\mathrm{Pa}$ raguay, estrechamente vinculado con el Río de La Plata por razones sobre todo históricas, aunque Rona sostuvo que en su región oriental sería totalmente voseante, habría coexistencia de $t u ́$ y vos en Asunción y otras poblaciones de orillas del rio Paraguay, en tanto tendria tuteo exclusivo la población de San Lázaro en la margen oriental del mismo rio, recientemente se ha afirmado que la zona voseante es aún más extensa y que la alternancia del vos, tú y usted se da en todos los niveles sociolingüísticos del país carac-

hispánicos, afrobispánicos y criollos, Madrid, 1978, págs. 118-138. Para el caso de Chile, véase La lengua castellana en Chile, Santiago, 1966, págs. 296-298 y 306-308, de Rodolfo Oroz.

B Véanse ejemplos en Alvar-Pottier, ob. cit., § 100-102.

- Idem.

7 Segín los trabajos de Luis E. Behares, «Estudio sociodialectológico de las formas verbales de segunda persona en el español de Montevideo» y de Adolfo Elizaincín y Olga Dlaz, «Sobre tuteo/voseo en el español montevideano*, incluidos en el volumen compilado por Adolfo Elizaincín, Estudios sobre el espafiol del Uruguay, I, Montevideo, 1980. Ya Rona se había referido al tuteo exclusivo del sub-dialecto ultraserrano en algunos trabajos como Aspectos metodologicos de la dialectologia bispanoamericana, Montevideo, 1958, y Geografia y morfología del voseo, ob. cit., entre otros. 
terizados por bilingüismo guarani-español, y que en estos mismos niveles son mayoría las formas verbales voseantes, todo lo cual hace necesario el estudio pormenorizado de los hechos, con enfoque sociolingüístico ${ }^{8}$.

2.3. En la Argentina el voseo pronominal es general en todas las regiones, clases sociales y estilos del discurso, a pesar de la presión escolar por imponer el uso del $t u ́$ hasta en los últimos tiempos. Si bien esto constituye un rasgo de unidad del diasistema, es en las formas verbales que acompañan al pronombre vos donde se presentan divergencias.

2.4. En el presente de indicativo se registran formas de voseo verbal diptongado (cantáis, tenéis, vivis, sois), de voseo verbal monoptongado (cantás, tenés, vivís, sos), predominantes en la Capital Federal y la región litoralpampeana, y algunos paradigmas mixtos. En el caso de las formas monoptongadas, hay distintos tipos de monoptongación en los verbos con vocal temática -e- (del tipo tener). Asi, aparecen las formas tenés o tenis en distintas zonas o con alternancias diastráticas, pero prevalecen las formas en -ís en la zona central, noroeste y de Cuyo, como en algunos otros paises americanos (Chile, Bolivia, Ecuador, Perú, Colombia y parte de América Central). La provincia argentina de Santiago del Estero, siempre con referencia al presente de indicativo, es una zona con formas híbridas, ya que con el pronombre vos aparecen las que corresponden al verbo en singular (cantas, tienes, vives, eres). En lengua rústica, además, existe un paradigma mixto en -áis, -is, -is (cantáis, tenis, vivis).

2.4.1. Las distintas formas verbales que acompañan al pronombre 'vos' en el presente del indicativo nos han permitido distinguir en Argentina cuatro zonas $^{9}$ : a) la de formas monoptongadas del tipo -ás, -és, -ís (cantás, tenés, vivis) que se usan en la región litoral-pampeana y el nordeste (provincias de Misiones y Corrientes, el este de Chaco y Formosa y el norte de Entre Ríos), las que se extienden gradualmente hacia el centro y norte del pais; b) el área de formas verbales también monoptongadas, pero con -ís para los verbos con vocal temática - $e$ - (cantás, tenís, viviss). Esta área abarca parte del noroeste (Tucumán) y Cuyo (sur de San Juan, Mendoza y norte del Neuquén) y parte también de la zona central (centro y noroeste de Córdoba y centro y norte de San Luis). En algunos casos, como en la ciudad de Tucumán, los hablantes de los niveles socioculturales alto y medio alternan esas formas con otras híbridas del tipo vos cantas, tienes, vives, eres, que llevan el verbo en singular, en tanto que las formas de los verbos con vocal -e- en el tema pueden ser -és o -is según se trate de hablantes de los niveles alto

- Asi lo expresa Germán de Granda en El español del Paraguay, Asunción, 1979, págs. 75-81.

- Véase nuestro trabajo «Sobre la variación diatópica del espańol en la Argentinas, ob. cit. 
y medio o bajo respectivamente. En el caso de los sociolectos alto y medio el paradigma es mayoritariamente semejante al de las regiones litoral-pampeana y nordeste, esto es, cantás, tenés, vivís ${ }^{10}$; c) la zona de voseo verbal con paradigma mixto (-áis, -is, -is, cantáis, tenis, vivis) en parte del noroeste, incluyendo la región que hemos llamado andina del norte (la mayor parte de Jujuy, Salta, La Rioja, Catamarca, oeste de Chaco y Formosa, centro y norte de San Juan); d) la provincia de Santiago del Estero, en la cual, según los datos que hasta ahora se tienen, se usa el pronombre vos con las formas verbales en singular (vos cantas, tienes, vienes, eres). Las formas monoptongadas, propias de la región litoral-pampeana, pueden oírse ya en San Luis y parte de Córdoba, en la zona central, así como en ciudades del noroeste como Tucumán, según dijimos.

2.4.2. Respecto del presente de subjuntivo, en la ciudad de Buenos Aires se prefieren en el nivel sociocultural alto las formas híbridas, con verbo en singular (vos cantes, vos tengas, vos vivas), especialmente entre los jóvenes y las mujeres, pero en general hay bastante oscilación entre las formas verbales singulares y plurales. En cuanto al imperativo, en el español porteño culto, predominan casi exclusivamente las flexiones de segunda persona plural (cantá, tené, viví).

Además, siempre en la ciudad de Buenos Aires, el pretérito simple admite oscilaciones de formas con $-s$ y $\sin -s$ (cantastes, cantaste) aún en el nivel culto, aunque en éste la mayoría $(88,73 \%$ ) emplea sólo la forma sin $-s$, mientras que entre los hablantes que muestran oscilación también prevalece esa forma $\sin -s^{11}$. Por otra parte, según algunos estudiosos, en el porteño habria dos construcciones de imperativo negativo frente al afirmativo cantá. Las construcciones negativas son no cantés, con valor fuerte de mandato y otra no cantes (con el verbo en singular), usada igualmente con valor de subjuntivo y con sentido de mayor cortesía que la anterior, con verbo en plural ${ }^{12}$.

10 Así lo señala E. Rojas en Aspectos del babla en San Miguel de Tucumán, Tucumán, 1980, págs. $77-80$.

11 Los datos son del trabajo de María Isabel Siracusa, «Morfología verbal del voseo en el habla culta de Buenos Aires», que integra el volumen editado por Juan M. Lope Blanch, Estudios sobre el español hablado en las principales ciudades de América, México, 1977, págs. 385-393.

12 M." Beatriz Fontanella de Weinberg, «La oposición "cantes/cantés" en el español de Buenos Aires», Thesaurus, XXXIV, 1979, págs. 72-83. El uso del presente de subjuntivo como imperativo negativo y sus usos 'propiamente subjuntivos' son diferenciados por M." Beatriz Fontanella de Weinberg y Beatriz Lavandera en Variant or morpheme? Negative commands in Buenos Aires spanish, Washington, D. C., 1975 (mm.). Sobre tratamiento de segunda persona singular en otra ciudad importante de la provincia de Buenos Aires, véase «Los pronombres de tratamiento en el español de Bahla Blanca», en Actas de la Quinta Asamblea de Filología y Literaturas Hispánicas, Bahía Blanca, 1968, págs. 142-151, de M." B. Fontanella de Weinberg y M. Najt. 
2.4.3. En Rosario, a 300 kilómetros al norte de la ciudad de Buenos Aires sobre el río Paraná, hemos trabajado no sólo con el nivel sociolingüístico culto sino con muestras que dan representación diastrática, además de generacional y de sexo. En el presente de indicativo prevalecen en esta ciudad las formas plurales monoptongadas (cantás, tenés, venis, sos) con el pronombre vos, aunque en el nivel culto haya apariciones minoritarias de híbridos como vos cantas en contextos formales. En cuanto al presente de subjuntivo, existe oscilación en el uso entre formas verbales de plural y de singular, aunque prevalecen las plurales, especialmente en los niveles medio y bajo, en los jóvenes $\mathrm{y}$ en contextos informales (vos cantés, vos tengás, vos vivás). En el imperativo son exclusivas las formas del plural (cantá, tené, viví) en todos los estratos socioculturales ${ }^{13}$. En cuanto a la alternancia -ste, -stes en el pretérito simple de indicativo, un reciente estudio ${ }^{14}$ nos ha mostrado que en la lengua rosarina, la forma $\sin -s$ es mayoritaria en el nivel sociocultural alto ( $91,36 \%$ de las ocurrencias), pero disminuye en los otros niveles, especialmente en el nivel medio $(71,6 \%)$. En el nivel bajo vuelve a elevarse el porcentaje de frecuencia real de la forma $\sin -s(89,47 \%)$, hecho que se vincula indudablemente con el avanzado proceso de elisión de la /-s/ final de palabra en ese estrato, hasta el punto de que puede pensarse que la forma con $-s$ existe como subyacente entre esos hablantes, pues los mismos reponen la $-s$ en el llenado de oraciones por escrito, por ejemplo. El trabajo incluye una indagación acerca de creencias y actitudes sobre estos hechos, resultando que hay mucha oscilación en la consideración de la forma con $-s$, aunque predomina su rechazo como estigmatizada.

2.4.4. En San Luis la forma con $-s$ aparece registrada en lengua rural sin excepciones ${ }^{15}$. La aparición de híbridos con el verbo en singular y el pronombre vos en el presente de indicativo (vos cantas, vos tienes) se han registrado hasta ahora, en el área litoral-pampeana y nordeste, en el nivel sociocultural culto y en contextos formales, según dijimos, pero no se mencionan en otras zonas, excepción hecha de la provincia de Santiago del Estero donde son comunes, pues en las demás las formas tengás o tengáis son las corrientes ${ }^{16}$. Por todo lo dicho, este rasgo morfológico que se refiere a las formas

13 La morfologla verbal al respecto está tratada en El español hablado en el litoral argentino. Formas personales del verbo, Rosario, 1977, y «Aspectos del español hablado en la Argentina», en LEA, II (2), 1980, págs. 299-346, ambos de N. Donni de Mirande. Para el voseo pronominal, véase el trabajo de Susana H. Boretti de Macchia El español hablado en el litoral argentino. El pronombre, Rosario, 1977.

14 Debido a Susana H. Boretti de Macchia y M. Cristina Ferrer de Gregoret y presentado al VII Congreso Internacional de ALFAL con el título de «En torno a la segunda persona singular del pretérito perfecto simple en el habla de Rosarios.

15 Vidal de Battini, El habla rural de San Luis, Buenos Aires, B.D.H. VII, 1949, pág. 122.

${ }_{16}$ Según datos de J. P. Rona en Geografía y morfología del voseo, ob. cit. En cier- 
verbales del presente que acompañan al voseo pronominal, puede considerarse como de diferenciación diatópica, diastrática y diafásica en el diasistema argentino. Sólo en el caso de las formas del imperativo, que han recibido atención en otras regiones del país, puede afirmarse que es general el uso de las que corresponden al plural (cantá, tené, viví), esto es, que sería un rasgo de unidad en el diasistema ${ }^{17}$. En lo que se refiere al uso de la forma con $-s$ en la segunda persona singular del pretérito simple de indicativo, la misma ha siclo señalada como de aparición más o menos frecuente en todo el país, por lo que sería un caso de fragmentación diastrática más que diatópica, a pesar de que en la lengua rústica de algunos rincones del centro, noroeste y Cuyo, aparecen ocasionalmente las formas diptongadas (cantasteis, tenisteis, vivisteis) con el pronombre vos. Las formas con $-s$ del pretérito simple, debidas a la analogia con las restantes segundas personas del paradigma verbal (con $-s$ ) a la que se agrega en las zonas voseantes la fuerza de la conservación de la $-s$ del plural de formas como vos tomastes de la época clásica, no desterradas aún en las zonas de tuteo pues se apoyan en todo el sistema verbal, aparecen, por lo demás, no sólo en Argentina sino en todo el ámbito del español popular americano y peninsular, asi como en el judeo-español, según lo señalan A. Rosenblat $\mathrm{y}$, más recientemente, M. Alvar y B. Pottier ${ }^{18}$.

2.5. Otro hecho que atañe a la morfologia verbal es la aparición de una -g- epentética en formas analógicas como haiga, haigas $\sim$ haigás, haigamos, haigan que en Rosario, por ejemplo, he recogido en los estratos socioculturales medio y bajo ${ }^{19} \mathrm{y}$ que también han sido anotadas en Tucumán como muy usadas por los hablantes del nivel sociocultural bajo ${ }^{20}$ o en Salta, donde

tos casos la información de Rona ha sido discutida y modificada por estudios monográficos más recientes.

17 Respecto de la forma negativa para el mandato, en Salta se ha señalado un uso distinto al de Buenos Aires. Alli se emplea no cantés como forma cortés, en tanto no cantes expresa una orden fuerte. Véase el trabajo de Juana Rodas de Bilén y Marta E. Torino, «La lengua y su reflejo de la realidad sociocultural salteña», en Estudio socioeconómico y cultural de Salta, II, Salta, 1982, págs. 5-102.

18 Rosenblat, ob. cit., págs. 222-228. Aquí estudia el autor la extensión de la variante -tes (tomates, cantates) en muchas áreas hispánicas americanas y peninsulares, explicándola por un mecanismo según el cual al aparecer una terminación con dos sibilantes (-stes), la conciencia idiomática se fijó en la final como indice de la segunda persona plural y eliminó a la primera. Sobre el problema de las desinencias del perfecto es importante lo que consignan Alvar y Pottier, ob. cit., § 134.

19 «El español hablado en el litoral argentino. Formas personales del verbo», ob. cit., pág. 19. También registré la forma báigamos con cambio acentual, que aparece en otras regiones hispánicas, pero no en el centro y noroeste de Argentina.

20 E. Rojas, ob. cit., pág. 155. Rosenblat, ob. cit., págs. $244-247$, trae riquísima documentación sobre baiga, vaiga, etc., y todas las formas verbales con - $g$ - epentética, analógicas, en los dialectos españoles americanos y peninsulares. También Alvar-Pottier, ob. cit., § 142.2, se refieren a verbos con esta particularidad en el español antiguo y en los dialectos actuales. 
haiga y haigan se registran en todos los niveles, incluyendo el culto, en tanto que haigás y haigamos sólo en el nivel medio y en el bajo ${ }^{21}$. De acuerdo con ello, la aparición de estas formas sería un caso de fragmentación diastrática más que diatópica.

2.6. Otro fenómeno que se extiende por todo el territorio argentino aunque con diferente distribución social, es la aparición de formas diptongadas, que son etimológicas, en el presente de indicativo y en el subjuntivo de verbos con $-e$ - y con -o- en el radical que pasan, entonces, a ser conjugados como irregulares. Tal el caso de enredar (enriedo, enriede), desenredar (desenrieda, desenriede), anegar (aniego, aniegue), esconder (escuendo, escuende) y algunos más. Estas formas se registraron en los niveles medio y bajo del español rosarino, así como en ciudades del noroeste, como Tucumán y Salta, apareciendo en esta última zona también en el nivel culto con mucha frecuencia ${ }^{2}$. Otras formas, en cambio, se han anotado en lengua rural de tipo vulgar de las regiones litoral-pampeana y del centro (San Luis), entre ellas entriego, entriegue, apriendo, apriende, dueblo, dueble, tueso, tuesa, ruempo, ruempe, pero hasta ahora no han sido mencionadas en lengua urbana ${ }^{23}$. Según esto, si bien el hecho de la diptongación en los presentes de indicativo $y$ de subjuntivo de estos verbos es un rasgo que aparece en casi todo el territorio argentino, en ciertos niveles socioculturales (diferenciación diastrática), hay algunos de ellos que ocurren sólo en lengua rural, lo que constituye un rasgo de diferenciación entre lengua urbana y lengua rural.

2.7. El fenómeno inverso, es decir, la falta de diptongación en las primeras y terceras personas del singular y segundas y terceras del plural del paradigma de los presentes de indicativo y subjuntivo de verbos con $-e$ - o con $-o$ en el tema que, así, pasan a ser conjugados como regulares (sin diptongación tampoco en la segunda persona singular por ser voseante) cuando no lo son en el español "normal", se registra en distintas zonas de Argentina. Nos referimos a verbos como emparentar (emparento, emparente), fregar (frego, fregue), apretar (apreto, aprete), refregar (refrego, refregue), helar (helo, hele), forzar (forzo, force), colar (colo, cole), engrosar (engroso, engrose), tostar (tosto, toste), oler (olo), y también hervir (hirvo, hirva), etc. En Rosario y todo el sur santafesino, así como en el norte de la provincia de Bue-

21 Rodas de Bilén y Torino, ob. cit., págs. 28 y 279-286.

22 E. Rojas, ob. cit., refiriéndose al habla de San Miguel de Tucumán, menciona la ocurrencia de la forma diptongada enriedo, pág. 146. Rodas de Bilén y Torino, ob. cit. registran las diptongaciones muy frecuentes de enredar, desenredar y enderezar en el nivel culto de Salta (provincia y ciudad).

$2 s$ E. Tiscornia, ob. cit., cits les formas entriega, tiempla, por ejemplo, en el gau. chesco, y Vidal de Battini, El espafiol de la Argentina, ob. cit., pág. 167, señala estas y otras formas similares como propias del habla rural, aunque hay datos actuales de su aparición en lenguas urbanas. 
nos Aires, he recogido estas formas en los estratos socioculturales medio y bajo, pero también en el hablar descuidado de hablantes cultos ${ }^{24}$, e igualmente han sido señaladas en la zona central del país (habla rural de San Luis, por ejemplo) y en el noroeste, tanto en lengua urbana como rural, así como en gran parte de América y, con menor difusión, en Canarias y la España Continental ${ }^{25}$. Pareciera, entonces, un rasgo de unidad diatópica argentina, aunque con diferenciación diastrática.

2.8. Un fenómeno morfológico con difusión más restringida, ya que sólo ha sido señalado en la región litoral-pampeana, es el uso de las formas antiguas y dialectales de los verbos decir y traer con diptongación analógica en la lengua de los estratos bajos. En la provincia de Santa Fe aparecen las formas dijieron, dijiera, dijiese, trajieron, trajiera, trajiese en lengua rural y urbana (niveles medio y bajo), y lo mismo ocurre en la provincia de Buenos Aires, siendo, por lo tanto, una característica de diferenciación diatópica y también diastrática. Por otra parte, estas formas ocurren en otras regiones hispánicas (en lengua popular) como México, América Central, Colombia, Venezuela, Ecuador, Chile, Castilla, Andalucía, Santander, Extremadura, Murcia, Salamanca, Cuenca, Cespedosa de Tormes y Zamora ${ }^{26}$.

2.9. Difusión más general tienen en Argentina las formas de compuestos del verbo decir y de terminados en -ducir que en el pretérito simple de indicativo se usan en sustitución de formas fuertes, por analogia con los verbos regulares, como ya lo hacían en el español antiguo, siguiendo el tema débil : bendeci, maldeci, conduci, introduci, reduci, produci (con las restantes personas) y otros similares. Estas formas débiles se emplean en la lengua de Rosario y otras ciudades de la provincia de Santa Fe (niveles socioculturales medio y bajo), así como en lengua rural, y en las provincias de Buenos Aires,

24 El español hablado en el litoral argentino. Formas personales del verbo, ob. cit., págs. 16-18.

${ }^{25}$ Véase de E. Rojas, ob. cit., pág. 146; de Rodas de Bilén y Torino, ob. cit., pág. 28; de Vidal de Battini, El habla rural de San Luis, ob. cit., pág. 125, y El español de la Argentina, ob. cit., pág. 167. Rosenblat trae documentación tanto sobre la diptongación cuanto sobre la falta de ella en el español antiguo y en el actual de Andalucía, Cespedosa de Tormes, Asturias, Nuevo México, México, América central, Colombia, Venezuela, Ecuador, Perú, Chile y Argentina (Notas de morfología dialectal, ob. cit., páginas 280-286). En Tenerife, M. Alvar registro formas como apreta, frego, tregue, etc., fuera de la norma prestigiosa, en su trabajo El español bablado en Tenerife, Madrid, 1959, pág. 53. En la isla de La Gomera, también del archipiélago canario, Carlos Alvar, recogió formas similares de fregar, sin diptongación, consignadas en Encuestas en Playa de Santiago (Gomera), Madrid, 1975, pág. 65.

26 Según lo documenta Rosenblat, ob. cit., págs. 297-298. Tanto él como Tiscornia, ob. cit., mencionan ocurrencias de estas formas en el gauchesco, es decir, en la lengua que reflejan el Martín Fierro y otros textos, referida a la zona rural de las provincias de Buenos Aires y norte de La Pampa actual. Hoy se han extendido estas formas a los niveles socioculturales bajos de la lengua urbana de la región litoral-pampeana. 
Entre Rios y otras de la zona litoral pampeana, pero también en la región central (provincia de San Luis) ${ }^{n}$ y en el noroeste (Salta y Tucumán, por ejemplo) ${ }^{28}$. En otras zonas hispánicas también ocurren, como en Chile, Colombia, Guatemala, Maragateria y Astorga. Igualmente se han documentado en Canarias y Andalucía y como tendencia vulgar en el dominio castellano ${ }^{29}$.

2.10. Si el anterior es un rasgo de unidad diatópica, aunque de diferenciación diastrática, el uso de formas como estea y dea constituye un elemento de divergencia diatópica y diastrática en el español de la Argentina. Estea y dea, en efecto, sólo se emplean en los estratos socioculturales bajos (lengua urbana y rural) del área litoral-pampeana y no en el centro y noroeste del país. Además, aparecen en el asturiano occidental, en el central, en Astorga y en el mirandés, ya sea con la variante conocida en nuestro país, ya sea como dia, estía o deia, esteia, según lo indican M. Alvar y B. Pottier ${ }^{30}$. A la inversa, ocurren en el centro y noroeste, pero son desconocidas en el resto de Argentina, las formas verbales de la segunda persona del futuro de indicativo en -is (cantaris, comeris, vivirís), que también se registran en Chile, Bolivia, Ecuador y Perú ${ }^{31}$.

2.11. Podriamos mencionar otras muchas características morfológicas del sistema verbal en la Argentina, algunas como rasgos de unidad y otras de diferenciación del diasistema (distintas desinencias de tiempos y modos, además de las mencionadas, cambios acentuales de diversos tipos, formas regularizadas de caber, andar y otros verbos, así como del futuro, alternancias vocálicas, conservaciones de antiguas formas romances y de vulgarismos dialectales, confusiones en la expresión del plural en verbos con enclíticos pronominales, etc.), pero creemos que lo ya señalado ilustra muy bien sobre la

27 Vidal de Battini, El habla rural de San Luis, ob. cit., pág. 129.

28 Rodas de Bilén y Torino, ob. cit., pág. 28, mencionan maldecí y otras formas semejantes en la ciudad de Salta, y E. Rojas, ob. cit., pág. 149, trae una lista de esas formas de compuestos de decir y terminados en -ducir, usadas en Tucumán.

29 Rosenblat, ob. cit., págs. 293-294. M. Alvar en El español bablado en Tenerife, ob. cit., pág. 56, y C. Alvar, ob. cit., pág. 66, mencionan formas de este tipo. Con estas formas de perfecto débil se relacionan los participios de esos y otros verbos (bendecido, maldecido, freido, imprimido, rompido, etc.) con eliminación de la diferencia temática de infecto y perfecto, las que hemos registrado en el sur santafesino, en los niveles medio y bajo de lengua urbana y en la lengua de la provincia de Buenos Aires. Es una antigua tendencia ya presente en el latín vulgar, que dio lugar a confusiones frecuentes en el romance del siglo $\mathrm{x}$ y se continúa posteriormente, apareciendo hoy en diversas zonas hispánicas en los participios constituidos sobre las formas débiles. Véase al respecto, las referencias sobre cambios temáticos del verbo en Alvar-Pottier, ob. cit., § 177-178.

so Ob. cit., § 147.

31 Vidal de Battini las señala en El habla rural de San Luis, ob. cit., págs. 122-123, como muy difundidas all $y$ en todo el noroeste argentino. Tambien Rosenblat, ob. cit., págs. 217-220, mencions formaciones de futuro en -is en Chile y Ecuador, además de la Argentina. 
complejidad de la morfología del sistema verbal argentino, sistema que muestra fragmentación geográfica y socio-dialectal, además de la incidencia de los distintos grados de estilo del discurso en algunos fenómenos.

3. Por ello, pasaremos a tratar ahora ciertos hechos que atañen a reducciones y variaciones en la totalidad del sistema, así como algunas cuestiones sintáctico-semánticas referidas al uso de tiempos y modos, punto en que es mucho menos abundante el caudal de información que tenemos.

3.1. En todo el país, y esto en los diversos niveles socioculturales y estilos del discurso, en el paradigma de los tiempos verbales se ha perdido la forma de segunda persona plural correspondiente al pronombre vosotros, apareciendo sólo ocasionalmente en algunas manifestaciones oratorias con confusiones frecuentes en el uso y en las concordancias con los pronombres. Por esa pérdida, las desinencias personales son sólo cinco, coincidiendo las plurales de segunda (usadas con el pronombre ustedes) y de tercera persona (usadas con los pronombres ellos/as). Este es un rasgo de absoluta unidad dialectal que se corresponde con lo que sucede en los demás países americanos, donde ustedes se emplea en función de plural único de vos, tú y usted, y en partes de España continental (Andalucía) y Canarias ${ }^{32}$.

3.2. Por otra parte, los datos hasta ahora conocidos sobre Argentina ${ }^{33}$ muestran que el total de formas del paradigma verbal se ha reducido al no usarse en la lengua hablada algunos tiempos, además de estar en decadencia otros y en general preferirse las formas simples a las compuestas, en los contextos que permiten tal sustitución. Como en gran parte del español americano $\mathrm{y}$ aún del español general ${ }^{34}$, se han perdido los futuros de subjuntivo (sim-

s2 Sobre la persistencia de ustedes en América véase Kany, ob. cit., págs. 77-79. Rosenblat, ob . cit., págs. 134-136 considera que no son totalmente iguales los usos del andaluz (y catalán) con los de América, ya que ustedes se correspondería con formas verbales de segunda o tercera personas del plural y no sólo de tercera, como en el hispanoamericano. Sin embargo, M. Alvar sefiala que en Tenerife, igual que en Andalucía, se emplea siempre el pronombre ustedes con la tercera persona del plural (ob. cit., pág. 52). Lo mismo señala C. Alvar, ob. cit., pág. 63.

33 Recordamos que no se han realizado hasta ahora trabajos completos con los modernos métodos de la geograffa lingüfstica en la Argentina. Los datos que se manejan aparecen en muy pocas obras de conjunto sobre el español de la Argentina o en monografías dialectales que últimamente han aumentado, pero que todavia dejan regiones sin estudiar, especialmente la cordillerana y gran parte del noroeste y nordeste.

* S. Gili y Gaya señala en Curso superior de sintaxis española, Barcelona, 1961, § 140 , que los futuros de subjuntivo desaparecieron de la lengua hablada de la mayor parte del dominio del español por ser innecesarios, ya que todos los tiempos del subjuntivo pueden expresar acción futura. A propósito de las reducciones del paradigma verbal del español contemporáneo y sus posibles causas, es interesante el trabajo de J. M. Lope Blanch sobre lo que sucede en México, «La reducción del paradigma verbal en el español de México», incluido en Estudios sobre el español de México, México, 1972, págs. 141155. También Kany, ob. cit., se refiere, entre otros, a ese hecho. Sobre el sistema verbal 
ple y compuesto), lo mismo que el pretérito anterior de indicativo, al menos en la lengua hablada de todas las regiones, niveles socioculturales y estilos ${ }^{35}$. Este rasgo de unidad del diasistema argentino está acompañado por otro, también de unidad, como lo es la decadencia de las formas en -se del imperfecto y pluscuamperfecto de subjuntivo, desplazadas por las formas en -ra. Esta tendencia, igualmente general en América, parece ser reducción antigua, pero no total, ya que, en Argentina y otras regiones, las formas en $-r a$ son preferidas pero no exclusivas, ya que se mantienen, aún en la lengua hablada, las terminadas en -se. En Rosario, por ejemplo, estas últimas conservan cierta vitalidad en el nivel sociocultural alto, especialmente en contextos formales; las formas en - $r a$ predominan, por el contrario, en el estilo informal de este nivel alto y en los otros niveles socioculturales, cualquiera sea el estilo del discurso. Además, la preferencia por las formas en $-r a$ se ha señalado en la zona central y del noroeste, también sin pérdida total de la forma en $-s e^{36}$.

3.3. Respecto del uso de los perfectos de indicativo (simple y compuesto), en Argentina hay tendencias a preferir uno $u$ otro de ellos en las distintas regiones, pero, en general, parecen olvidadas o poco claras las diferencias aspectuales y temporales entre ambos, diferencias que se mantienen, en cambio,

en el español mexicano hay estudios extensos como el de José $\mathrm{G}$. Moreno de Alba, $\mathrm{Va}$ lores de las formas verbales en el español de México, México, 1978, y también, para las formas no personales, el de Elizabeth Luna Traill, Sintaxis de los verboides en el babla culta de la ciudad de México, México, 1980. Sobre Rosario (Argentina), el trabajo El español hablado en el litoral argentino. Formas personales del verbo, de N. Donni de Mirande, ob. cit. Las formas no personales en esa misma ciudad, son tratadas en «Usos y valores de las formas no personales del verbo en el español hablado en Rosario», también de Donni de Mirande, Rosario, 1982.

${ }_{35} \mathrm{Al}$ respecto dice Vidal de Battini, El español de la Argentina, ob. cit., pág. 166, que el pretérito anterior se usa poco. Sin embargo, en Rosario no hemos registrado el uso de este pretérito en la lengua hablada, y lo mismo pasa en Tucumán, según E. Rojas, ob. cit., pág. 143, y en Salta, Rodas de Bilén y Torino, ob. cit., pág. 27.

s6 Véanse las obras citadas de E. Rojas para Tucumán (pág. 156), de Rodas de Bilén y Torino para Salta (pág. 27); de Vidal de Battini, El babla rural de San Luis, ob. cit., pág. 393, para lo que ocurre en esa parte de la zona central, y de N. Donni de Mirande, El español bablado en el litoral argentino. Formas personales del verbo, ob. cit., pág. 56. Rosenblat, en sus Notas de morfología dialectal, págs. 214-216, menciona la preferencia por la forma en ra en toda Hispanoamérica, además de la pérdida del futuro de subjuntivo en $-r e$, lo cual se produce también en algunas regiones de España (Maragatería y Astorga). Kany, ob. cit., págs. 221-223, se refiere a esta característica del español americano (preferencia por las formas en -ra), por oposición a su predominio en España, según observación antigua de Cuervo y más reciente de Gili y Gaya, ob. cit., $\S 137$. También Kany se refiere a la pérdida del futuro de subjuntivo en -re, muy raro ya en España, aunque se mantiene en algunas regiones hispanoamericanas como Santo Domingo, alto Ecuador y otras, especialmente en lengua escrita. Sobre este último problema, G. de Granda, en «Formas en -re en el español atlántico y problemas conexos», recogido en sus Estudios lingüísticos hispánicos, afrobispánicos y criollos, ob. cit., páginas 95-117, ha sostenido que la pervivencia de esa forma en regiones americanas, sobre todo de América central, y en Andalucía y Canarias, sería un rasgo del español atlántico. 
en otras partes de Hispanoamérica, como México por ejemplo, y en zonas de España ${ }^{37}$. En la región litoral-pampeana argentina, y en esto coincide con muchas partes de Hispanoamérica, Canarias y aún con regiones de España continental, se prefiere el uso del pretérito simple. En Rosario y el sur de la provincia de Santa $\mathrm{Fe}$, que integran esa región litoral-pampeana, la diferencia semántica entre los dos pretéritos se neutraliza y aparece con más frecuencia el pretérito simple (canté) que indica genéricamente un pasado realizado. Esto ocurre sobre todo en contextos informales de todos los niveles socioculturales, en tanto que en estilo formal (nivel culto) tiene algo más de frecuencia la forma compuesta (38\% de ocurrencias frente a $62 \%$ de la simple). Esta forma compuesta se emplea para señalar mayor aproximación del enunciado respecto del hablante, es decir, tiene un sentido de conexión con el presente (presente resultativo): he venido para estar presente en esta celebración, por ejemplo ${ }^{38}$. En cambio, en todo el noroeste del país, especialmente desde Tucumán hacia el norte, hasta la frontera con Bolivia, se prefiere la forma compuesta (he cantado) y esta tendencia se continúa en Bolivia, Perú y otras áreas limitadas. En el noroeste de la provincia de Córdoba también prevalece la forma compuesta, en tanto que en la región central (centro y sur de Córdoba y la provincia de San Luis) alternan las dos formas, aunque hay inclinación hacia el uso de la forma simple, uso propio de

37 Sobre el español peninsular, Keny, ob. cit., págs. 199-202, sostiene que la diferencia subsiste en Navarra, Aragón y Castilla la Vieja y en América es corriente en Perú, Bolivia, el noroeste de Córdoba (Argentina) y algunas otras áreas limitadas. En La Gomera (Canarias) hace C. Alvar, ob. cit., pág. 82, la observación de que predomina el perfecto simple y desaparece entre esta forma y la compuesta, en parte, la diferencia como en muchas regiones hispanoamericanas y entre los castellano-hablantes de Asturias y Galicia. M. Alvar señala que en Tenerife se prefiere el perfecto simple (ob. cit., página 78). También en Chile R. Oroz, ob. cit., pág. 383, menciona que hay preferencia por el pretérito perfecto simple. J. M. Lope Blanch describe el estado de cosas en México, sosteniendo que alli se conservan diferencias temporales entre las formas simples y compuestas del pretérito, aunque se prefiere la forma simple. Véase su trabajo «Sobre el uso del pretérito en el español de México», en Estudios sobre el español de México, ob. cit., págs. 127-139. Moreno de Alba, ob. cit., págs. 63-68, sostiene que en el dialecto mexicano las expresiones en que aparece la forma compuesta son, en cierta medida, excepcionales, pues se prefiere el perfecto simple y menciona diferencias de sentido entre ambas formas. Sobre el uso de estas formas han tratado detenidamente. E. Alarcos Llarach, «Perfecto simple y compuesto en español», RFE, XXXI, 1947, págs. 108-139, y en varios trabajos que integran el volumen Estudios de gramática funcional del español, Madrid, 1970; M. Criado de Val, en El verbo español, Madrid, 1968; S. Gili y Gaya, ob cit., § 122 y 123, entre otros. E. Lorenzo expresa su creencia de que la forma compuesta desaparecerá en un futuro, al menos en el español hablado, en $E l$ español de boy, lengua en ebullicion, 2." ed., Madrid, 1971. Nosotros sañalamos en nuestros trabajos sobre el verbo en Rosario, la decadencia general de las formas compuestas que tienden a ser sustitufdas por las formas simples en todos los casos posibles.

B8 El español bablado en el litoral argentino. Formas personales del verbo, de Donni de Mirande, ob. cit., págs. 46-48. 
la región litoral-pampeana. Son tan notables las preferencias regionales por uno u otro pretérito perfecto que cuando los hablantes del litoral y el sur del país quieren imitar a los originarios del noroeste utilizan el pretérito compuesto y viceversa ${ }^{39}$.

3.4. En cuanto al uso de las formas del futuro de indicativo (simple y compuesto), en todo el país existe la tendencia a reemplazar sus dos formas por perífrasis. En el caso del futuro simple, cuando expresa acción futura absoluta o mandato, suele ser sustituido por el presente de indicativo (mañana vamos) o por perifrasis como: ir + a + infinitivo (voy a ir, vas a ir, como mandato esta última expresión); haber $+\mathrm{de}+$ infinitivo (lo he de ver); pensar + infinitivo (pienso ir después); querer + infinitivo (quiero ir mañana); deber $+(\mathrm{de})+$ infinitivo (debe de venir mañana, debe venir mañana). El futuro compuesto se reemplaza por perífrasis como: deber $+(\mathrm{de})+$ haber + participio (debe (de) haber sido mucho más lindo); haber $+\mathrm{de}+$ haber + participio (ha de haber venido después que yo llegué); ir a + tener + participio (se lo voy a tener completo para mañana).

Esta tendencia a sustituir el futuro por perífrasis, por lo demás, es muy antigua. Está presente, como sabemos, ya en el latín, y continuó en las lenguas románicas. En español actuó desde sus orígenes, dando por resultado distintas soluciones dialectales, y opera hoy con el renovado uso de perifrasis de distinto tipo (progresivas, incoativas, obligativas o meramente temporales) en el español hablado en todas partes, pero con mayor frecuencia en Hispanoamérica. En Argentina no es fácil establecer condicionamientos, lingüísticos o extralingüísticos, que incidan en la preferencia por distintas construcciones, por lo que podría tratarse de una distribución libre (origen de un polimorfismo), como también se ha señalado en México ${ }^{40}$.

Con sentido de probabilidad, también se sustituye el futuro por perífrasis, pero aquí sí hay diferenciación geográfica en el diasistema argentino, ya que ello ocurre en el noroeste (han de ser las cuatro), pero no en el área litoralpampeana, donde se usa la forma sintética (serán las cuatro) ${ }^{41}$.

3.5. Por último nos referiremos a un hecho sintáctico que ha sido estudiado con algún detenimiento en las ciudades de Buenos Aires y Rosario y

39 Así lo recuerda E. Rojas, ob. cit., págs. 147-150.

40 Moreno de Alba, ob. cit., págs. 89-100. Véase también Kany, ob. cit., págs. 189. 193; Gili y Gaya, ob. cit., § 127-131; Alarcos Llorach, Estudios de gramática funcional del español, ob. cit.; Alvar-Pottier, ob. cit., § 159-162, para la evolución histórica del futuro en español. Para estos y otros usos en el español hablado coloquial (informal) es útil la obra de Brian Steel, A manual of colloquial spanish, Madrid, 1976.

11 Véanse de Vidal de Battini, El español de la Argentina, pág. 189, y El babla rural de San Luis, pág. 388; de E. Rojas, ob. cit., pág. 152. Lo mismo ocurre en Chile y otras regiones, según $R$. Oroz, ob. cit., pág. 384 . En Rosario, he registrado una perifrasis no con baber sino con deber para el futuro de probabilidad: deben ser las cuatro. 
señalado genéricamente en otras regiones. Es el uso de las formas en -ría (simple y compuesta) en la prótasis de períodos condicionales: si tendría ganas lo haría, si habría querido lo conseguiria (hubiera conseguido). A pesar de haber sido este uso indicado como frecuente en la lengua popular de Buenos Aires y Rosario, no es privativo del área litoral-pampeana, ya que se registró en el noroeste (Tucumán, por ejemplo) y en la zona central (San Luis) ${ }^{42}$. Fuera del país, estas construcciones aparecen en Chile (isla de Chiloé y Punta Arenas, en el extremo austral), Ecuador, sur de Colombia, Guatemala y Santo Domingo, así como en el norte de España, sobre todo en las provincias vascongadas y zonas limitrofes ${ }^{43}$.

En las ciudades argentinas de Rosario y Buenos Aires, la existencia de las formas en -ría en la prótasis de condicionales podría ser un caso especial de la alternancia entre modo indicativo y modo subjuntivo con gradual debilitamiento del segundo, siendo la variación en la prótesis un hecho recurrente en la historia del latín y de las lenguas romances. Pero creemos que en este caso especial tiene gran parte, además, la atracción analógica de la forma en -ría de la apódosis de estos períodos condicionales. En la ciudad capital de la Argentina, el estudio del fenómeno muestra que los hablantes del nivel sociocultural bajo son quienes más promueven este uso, así como las mujeres y que el proceso parece estar avanzando al ser los adolescentes y jóvenes quienes más emplean las formas en -ría en la prótasis, decreciendo el uso al aumentar la edad y el nivel de educación ${ }^{44}$. En Rosario, un reciente estudio muestra que, aún cuando sigue siendo minoritario el empleo de las formas en -ría en estas construcciones frente al subjuntivo en -ra, es frecuente en los niveles socioculturales medio (18\% de ocurrencias) y bajo (25\%) y también aparece en nivel alto (7\%). Las generaciones jóvenes son las que más utilizan estas formas en -ría en la prótasis de condicionales y promueven el uso más los hombres que las mujeres, al contrario de lo que sucede en Buenos Aires. De acuerdo con ello, pareciera que el proceso

\footnotetext{
4 E. Rojas, ob. cit., pág. 153; Vidal de Battini, El babla rural de San Luis, página 389 .

4s Kany, ob. cit., págs. 197-198. En Argentina las formas en -ria, en este y otros casos, parecen difundirse cada vez más en detrimento de las formas en ra y en -se del subjuntivo, al contrario de lo que sucede en México, según Lope Blanch, La reducción del paradigma verbal en el espafiol de México, ob. cit., págs. 145-146 y 148. Gili y Gaya, ob. cit., § 129 y 131, expresa que las formas simples con ría en la prótasis de condicionales aparecen en el habla vulgar del país vasco y zonas limítrofes y las compuestas, también, en las provincias vascongadas.

4 Véase el análisis semántico y sociolingüfstico que hace B. Lavandera de esta variación en el trabajo *Análisis semántico de la variación en tiempos verbales: oraciones condicionales en espafiol», incluldo en Variación y significado, Buenos Aires, 1984, páginas 21-36.
} 
está avanzando, pero ello en el futuro es dudoso, ya que hay conciencia lingüistica sobre su condición de hecho estigmatizado ${ }^{45}$.

4. Con este tal vez rasgo de unidad diatópica del español en la Argentina, aunque de diferenciación diastrática, terminamos el examen de algunos aspectos de nuestro sistema verbal, aspectos que ejemplifican la necesidad de tratar la lengua como un complejo dialectal y nunca como una estructura homogénea aún dentro de los límites políticos de un país americano. Y este complejo dialectal nos va constantemente descubriendo elementos que nos distinguen dentro y fuera del país y que se unen a la espesa trama de los que nos acercan a nuestros hermanos de Hispanoamérica, Canarias y España continental para constituir el entrañable lazo del idioma común.

4s Así lo consigna el estudio Acerca de la correlacion temporal potencial simple / potencial simple en el pertodo bipotético en Rosario, de M.' C. Ferrer de Gregoret y Carmen Sánchez, Rosario, 1984 (mm.). 